\title{
Perancangan Kerangka Crowdsourcing Berbasis Wisdom Of Crowds Untuk Kamus Naskah Lontar (Takepan) Sasak Online
}

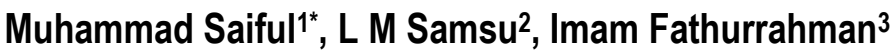 \\ 1,2Program Studi Sistem Informasi, Universitas Hamzanwadi \\ 3Program Studi Teknik Informatika, Universitas Hamzanwadi \\ *saipulsbm@gmail.com
}

\begin{abstract}
Abstrak
Kamus naskah Lontar (Takepan) Sasak online yang tersedia saat ini belum cukup memadai untuk dapat menjadi rujukan bagi masyarakat yang ingin mempelajari bahasa sangsekerta karena terbatasnya kontributor dan stagnannya kontribusi. Di sisi lain, penutur aktif naskah Lontar (Takepan) Sasak yang terekspos dengan internet tersedia dalam jumlah yang belum memadai. Mekanisme crowdsourcing berbasis wisdom of crowds diharapkan mampu menjadi solusi terhadap permasalahan tersebut. Makalah ini menyajikan rancangan kerangka sistem crowdsourcing kamus naskah Lontar (Takepan) Sasak online. Rancangan kerangka ini diharapkan dapat menjadi landasan pengembangan kamus naskah Lontar (Takepan) Sasak online yang baru. Dan adapun tujuannya adalah menjaga kelesatrian nilai - nilai budaya masyarakat sasak seperti nilai hubungan manusia dengan Tuhan dan nilai hubungan manusia dengan sesama. Adapun data pendukung dalam penelitian ini dikumpulkan melalui kajian pustaka terhadap berbagai referensi tertulis. Data-data itu kemudian dianalisis untuk mendukung kajian ini. Hasil yang diharapkan dalam pengembangannya dapat mempermudah masyarkat dalam mempejari dan mengkaji melalui media online tentang kamus naskah lontar (takepan) Sasak. Jadi kesimpulannya adalah bahwa dalam rancangan kerangka sistem crowdsourcing kamus naskah Lontar (Takepan) Sasak online diperlukan adanya pengembangan dengan tujuan untuk memperbaharui sisi kekurangannya, dan juga mempermudah pengguna yang ingin mempelajari dan mengkaji serta menterjemahkan aksara sansekerta melalui media online.
\end{abstract}

Kata kunci : Crowdsourcing, knowledge management, wisdom of crowds, design science, naskah Lontar (Takepan) Sasak, Kamus.

\begin{abstract}
He online Lontar (Takepan) Sasak manuscripts currently available are not sufficient to be a reference for people who want to learn Sanskrit because of limited contributors and stagnant contributions. On the other hand, active speakers of Lontar (Takepan) Sasak manuscripts exposed to the internet are available in insufficient numbers. The wisdom of crowds-based crowdsourcing mechanism is expected to be a solution to the problem. This paper presents a draft framework of the Sasak Lontar (Takepan) online crowdsourcing dictionary system. The design of this framework is expected to be the basis for the development of the new Sasak Lontar (Takepan) online dictionary. And as for the purpose is to preserve the diversity of Sasak people's cultural values such as the value of human relations with God and the value of human relations with others. The supporting data in this study were collected through a literature review of various written references. The data is then analyzed to support this study. The expected results in its development can facilitate the community in learning and studying through online media about the Sasak lontar (Takepan) dictionary. So the conclusion is that in the framework design of the Sasak Lontar (Takepan) online dictionary crowdsourcing system, development is needed in order to update the flaws, and also make it easier for users who want to learn and study and translate Sanskrit characters through online media.
\end{abstract}

Keywords: Crowdsourcing, Knowledge Management, Wisdom of Crowds, Design Science, Sasak Lontar (Takepan) Script, Dictionary. 


\section{Pendahuluan}

Naskah Lontar (Takepan) Sasak adalah tulisan Hanacaraka berbahasa Sangsekerta yang dipertuturkan oleh masyarakat suku sasak yang mendiami pulau Lombok, Nusa Tenggara Barat. naskah ini masih dipergunakan secara aktif dalam kegiatan budaaya masyarakat di pulau Lombok dan bahkan dijadikan salah satu mata pelajaran pada kurikulum sekolah lokal.[1] Ironisnya, hingga saat ini tidak mudah menemukan rujukan yang layak untuk mempelajari naskah Lontar (Takepan) Sasak di ranah online, terutama dalam bentuk kamus naskah Lontar (Takepan) Sasak.

Saat ini telah terdapat usaha untuk mendigitalkan kamus naskah Lontar (Takepan) Sasak dan menyediakannya secara online seperti pada situs kbs.sasak.org yang diprakarasai oleh Komunitas Sasak. Untuk penyusunan kamus tersebut, sasak.org mengandalkan penambahan kosakata oleh beberapa kontributor ke dalam sistem. Menggunakan model ini, sejak tahun 2008 di hingga akhir 2013 kamus tersebut hanya mampu menyediakan 1.516 kosakata. Kosakata tersebut disumbangkan hanya oleh 4 orang kontributor dengan aktivitas terakhir tercatat pada Januari 2012.[2] Selain menunjukkan bahwa kuantitas kosakata pada kamus tersebut masih rendah, juga terjadi stagnasi penambahan kosakata oleh kontributor yang ada.

Di sisi lain, pemanfaatan kolaborasi masal melalui internet yang lebih dikenal dengan nama crowdsourcing untuk pemecahan persoalanpersoalan di berbagai bidang telah terbukti keberhasilannya.[3],[4],[5],[6] Keberhasilan ini juga tidak terlepas dari fenomena wisdom of crowds dimana pengetahuan dari para kontributor berhasil diagregasikan untuk menghasilkan produk yang berkualitas. [5],[7],[8] Beberapa contoh keberhasilan ini antara lain dapat diwakili oleh Wikipedia, IStockPhoto, Amazon MechanicalTurk, ReCaptcha, dan OpenStreetMap.[4]

Makalah ini mencoba menyajikan alternatif rancangan untuk kamus naskah Lontar (Takepan) Sasak online dengan memanfaatkan mekanisme crowdsourcing yang berpegang pada prinsip-prinsip pencapaian wisdom of crowds. Penggunaan mekanisme crowdsourcing dan prinsip pencapaian wisdom of crowds pada kamus tersebut diharapkan dapat mengatasi kelemahan pada model sebelumnya terutama dari sisi jumlah kontribusi dan kontributor pada sistem.

Perancangan dilakukan dengan berpedoman untuk perancangan sebuah sistem kolaborasi masal untuk pencapaian wisdom of crowds dengan tujuan menghasilkan artifak berupa kerangka kamus naskah Lontar (Takepan) Sasak online, dengan menggunakan kerangka design science dalam penelitian sistem informasi [6].[7],[9] Hasil dari rancangan ini, selain diharapkan dapat menjadi pedoman untuk pengembangan kamus naskah Lontar (Takepan) Sasak online yang baru, juga diharapkan mampu memperkaya basis pengetahuan terkait 
bagaimana merancang sebuah sistem yang memanfaatkan mekanisme crowdsourcing dan fenomena wisdom of crowds untuk dapat mencapai tujuannya.

\section{Tinjauan Pustaka}

\subsection{Penelitian Terkait}

- Sutriandi, A. Editri. 2010. Pengembangan Model Pencapaian the Wisdom of Crowds pada Wikipedia dalam Kaitannya dengan Wikipedia sebagai Sistem Terapan Computer Supported Cooperative Works. ITB : Tesis Magister.

- Samsu, L. M, Sutriandi, A. Editri, and Ahmad, Ramli. 2014. Perancangan kerangka Crowdsourcing Berbasis Wisdom of Crowds untuk Bahasa Sasak Online. Procceding. KNSI.

\subsection{Landasan Teori}

1. Kamus Naskah Lontar (Takepan) Sasak dan Peluang Crowdsourcing

Sebuah kamus dapat dikategorikan sebagai sebuah artifak berupa basis pengetahuan tekstual. Bagian utama sebuah kamus terdiri atas daftar isian atau disebut sebagai struktur makro sebuah kamus. Setiap isian dapat dikaitkan dengan pengetahuan terstruktur berupa atribut seperti lemma, makna/definisi, dialek, jenis kata, pelafalan, lemma, sinonim, antonim dan atribut-atribut lainnya yang dikenal sebagai struktur mikro sebuah kamus. Sebuah kamus minimal memiliki lemma - definisi - contoh penggunaannya .[10] Pada kamus naskah Lontar
(Takepan) Sasak online yang ada saat ini, struktur mikro yang tersedia antara lain lemma, definisi (bilingual), pelafalan beserta sinonim dan antonimnya. Meski demikian struktur mikro tersebut tidak tersedia untuk seluruh isian yang ada.

Terkait naskah Lontar (Takepan) Sasak, perhatian khusus diberikan pada keragaman dialek. Naskah Lontar (Takepan) Sasak dikenal memiliki empat variasi dialek utama yakni MenóMené, Meriaq-Meriku, Menu-Meni, dan NgenóNgené .[11] Hal ini harus mendapatkan perhatian secara khusus dalam perancangan kamus agar setiap isian kamus dapat diidentifikasi berasal dari dialek yang mana.

Karena naskah Lontar (Takepan) Sasak masih digunakan secara aktif oleh masyarakat di pulau Lombok, para penuturnya tersedia dengan jumlah yang signifikan pada setiap generasi. Kondisi ini memberikan keuntungan dari sisi peluang bahwa setiap penduduk suku sasak yang terekspos dengan internet memiliki kemampuan bernaskah Lontar (Takepan) Sasak aktif .[1] Dari halaman facebook komunitas yang terafiliasi langsung dengan suku Sasak, didapatkan angka sebesar 4.581 pengguna facebook pada Komunitas Sasak [9], 4.208 secara eksplisit menyukai topik ini, dan sekitar 230.000 pengguna facebook menggunakan bahasa ini. Angka-angka ini menunjukkan potensi besar pengguna dan kontributor untuk sistem crowdsourcing kamus naskah Lontar (Takepan) Sasak secara online. 


\section{Crowdsourcing \& Wisdom of Crowds.}

Istilah crowdsoucing mulai dipopulerkan oleh Jeff Howe pada tahun 2006, melalui artikel pada Wired Magazine.[9] Crowdsourcing didefinisikan model pemecahan masalah dan pembuatan produk secara online dan terdistribusi, mengalihkan tugas yang tadinya dikerjakan oleh para karyawan ke khalayak ramai .[12] Menurut Istilah crowdsoucing bahkan dapat diidentikkan dengan istilah populer lainnya termasuk di antaranya peer-production, collective intelligence, smart mobs, dan collaborative systems. [3]

Kolaborasi masal para pengguna atau kontributor sistem dapat hadir dalam bentuk eksplisit seperti evaluasi (review, vote, tag), berbagi (benda, pengetahuan), membangun jaringan, membangun artifak (software, sistem, pengetahuan) atau eksekusi pekerjaan tertentu dengan kemungkinan yang tidak terbatas.[3] Kolaborasi tersebut juga dapat hadir dalam bentuk implisit, dimana crowdsourcing menumpang pada sistem lain dan merupakan produk sampingan dari aktivitas pada sistem tersebut seperti yang diterapkan pada usaha digitalisasi konten melalui re-captcha dan koreksi ejaan pada search engine.[4]

Pada jenis sistem crowdsourcing tertentu, kesuksesan crowdsourcing tidak dapat dilepaskan dari sebuah fenomena yang dikenal dengan nama Wisdom of Crowds.[13] Wisdom of crowds dapat dijelaskan sebagai fenomena konstruksi pengetahuan oleh individu-individu yang berkolaborasi secara terpisah-pisah. Istilah ini pertama kali diangkat oleh Surowiecki yang mengatakan bahwa pada kondisi tertentu sutu kelompok dapat menjadi lebih pintar daripada individu terpintar pada kelompok tersebut dalam pemecahan masalah tertentu.[13] Contoh yang paling populer dan relevan dengan makalah ini adalah Wikipedia sebagai sebuah usaha untuk membangun basis pengetahuan tekstual.[7]

Untuk membangun sistem crowdsourcing yang efektif, menurut [4] terdapat beberapa tantangan yang perlu dijawab saat akan merancang sistem antara lain : (1) Bagaimana cara merekrut dan mempertahankan pengguna? (2) Bagaimana pengguna berkontribusi? (3) Bagaimana cara menggabungkan hasil kontribusi pengguna? dan (4) Bagaimana cara melakukan evaluasi pengguna beserta kontribusinya?

Merekrut dan mempertahankan pengguna sangat vital karena tanpa tercapainya angka kritis (critical treshold) jumlah pengguna pada suatu sistem crowdsourcing, kuantitas dan kualitas hasil kontribusi yang diharapkan tidak akan tercapai. Contoh alternatif pilihan yang dapat dilakukan untuk merekrut pengguna antara lain merekrut sukarelawan, membayar pengguna, memaksa pengguna untuk berkontribusi sebelum mendapatkan layanan tertentu, dan terakhir dengan menumpang pada sistem lain untuk menjaring kontribusi. Contoh alternatif pilihan metode untuk mempertahankan pengguna dapat dengan menampilkan dampak dari hasil kontribusinya secara instan, 
memberikan rasa nyaman dan pengalaman menyenangkan saat menggunakan sistem, membuat kompetisi dan memberikan reputasi atau penghargaan kepada pengguna berdasarkan tingkat kontribusinya.[4][14]

Dalam membangun basis pengetahuan pengguna dapat berkontribusi dengan berbagai cara. Jika pengguna dibedakan atas beberapa kelompok, maka tiap kelompok dapat diberikan peran yang berbeda. Peran penambahan elemen pengetahuan, peran evaluasi, peran penggabungan kontribusi, penyelesaian konflik pada input dan lainnya. Peran yang membutuhkan beban kognitif ringan sebaiknya diberikan pada kelompok pengguna biasa. Bagi kelompok pengguna ini semakin sederhana mekanisme kontribusinya, semakin besar kemungkinan mereka mau berkontribusi. Peran yang membutuhkan beban kognitif berat bisa dibebankan pada kelompok pengguna yang diidentifikasi memiliki dedikasi tertentu terhadap sistem. [4][15]

Untuk menggabungkan hasil kontribusi seluruh pengguna, mekanisme yang dapat digunakan dapat berwujud sederhana dan terotomasi atau kompleks dan membutuhkan campur tangan pengguna lain. Hal ini berkaitan dengan jenis kontribusi yang digabungkan dan bagaimana bila para pengguna memiliki kontribusi solusi berbeda pada isu yang sama (konflik). Isu konflik kemudian berkaitan dengan isu evaluasi terhadap pengguna dan kontribusinya. Evaluasi dapat dibebankan kepada pengguna lain misalkan dengan voting, flag, rating baik terhadap individu pengguna maupun kontribusinya .[3]

Agar crowds dapat mencapai titik wisdom, menurut Surowiecki ada empat prasyarat yang harus dipenuhi. Empat prasyarat tersebut adalah diversity atau keragaman kognitif, Independence atau kebebasan masing-masing individu dalam kelompok tersebut, decentralization sehingga memungkinkan penilaian berdasarkan pengetahuan lokal, dan aggregation sebagai mekanisme untuk mentransformasi pengetahuan seluruh anggota kelompok menjadi satu kesatuan .[13] Seperti ditunjukkan oleh Sutriandi perancangan sebuah system crowdsourcing hendaknya mempertimbangkan karakteristik yang dapat digunakan untuk mendukung tercapainya empat kondisi tersebut.[7].

\subsection{Tahapan Penelitian}

Struktur sebuah kamus dan karakteristik yang dimiliki naskah Lontar (Takepan) Sasak dan merupakan bahan pertimbangan dalam perancangan kerangka kamus naskah Lontar (Takepan) Sasak. Perancangan dilakukan dengan analisis karakteristik sistem yang mampu menjawab tantangan sebuah sistem crowdsourcing dan di saat yang sama mencoba mendukung empat kondisi pencapaian wisdom of crowds. Gambar.1 menunjukkan peta karakteristik sistem hasil rancangan beserta kaitannya dengan pencapaian wisdom of crowds. 
1. Cara mendapatkan kontributor

Target pengguna sebagai kontributor sistem adalah mereka yang aktif bernaskah Lontar (Takepan) Sasak dan terekspose dengan internet. Mereka dapat direkrut sebagai sukarelawan dengan cara mempromosikan sistem pada website dan jejaring sosial tempat mereka berkumpul dan berinteraksi. Termasuk diantaranya adalah bila dilakukan kerjasama dengan komunitas tertentu (rekomendasi : sasak.org) dan mengaplikasikan fitur sosial pada sistem (rekomendasi : facebook social plugin) untuk menyasar jejaring yang dimiliki oleh seorang kontributor. Potensi 230.000 pengguna bernaskah Lontar (Takepan) Sasak pada facebook diharapkan akan menjadi jaminan keragaman kontributor sebagai pendukung pencapaian wisdom of crowds.

\section{Cara mempertahankan kontributor}

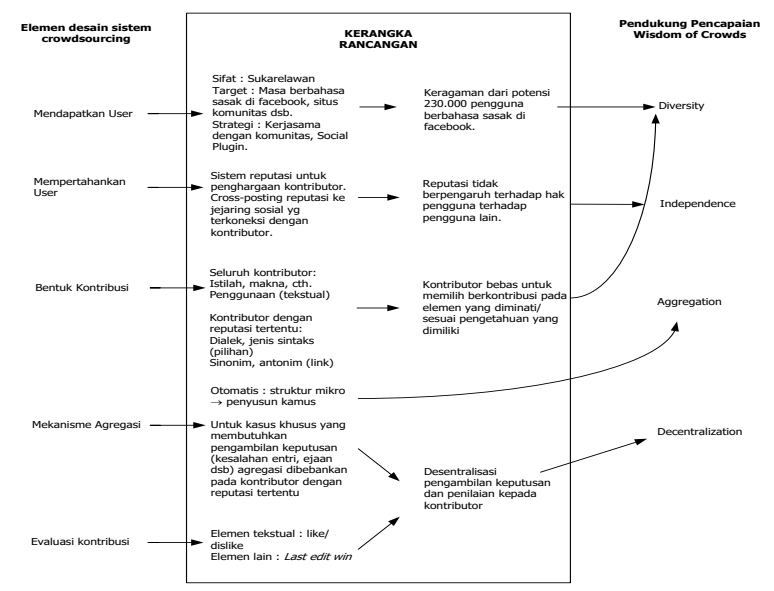

Gambar 1. Kerangka rancangan kamus base sasak online

Sistem dapat mempertahankan kontributor dengan memberikan apresiasi terhadap kontribusi mereka. Untuk dapat memberikan apresiasi sesuai dengan kontribusi pengguna, sistem harus mencatat tiap kontribusi yang telah dilakukan oleh pengguna. Bentuk apresiasi tersebut dapat berupa penyematan status/reputasi tertentu kepada kontributor yang telah mencapai jumlah dan jenis kontribusi tertentu. Penyematan status tersebut kemudian dapat diumumkan oleh sistem ke jejaring kontributor bila profil kontributor bersangkutan terasosiasi dengan jejaring sosial tertentu. Namun, untuk menjaga independensi antar kontributor, status/reputasi tersebut tidak memberikan hak lebih seorang kontributor terhadap kontributor lainnya.

\section{Bentuk kontribusi yang dapat diberikan}

Kontribusi yang dapat diberikan pada sistem dapat berupa elemen struktur mikro sebuah kamus. Elemen mikro tersebut, berdasarkan jenis kontribusinya dapat dikelompokkan menjadi elemen tekstual dan elemen non-tekstual. Elemen tekstual contohnya kosakata/lemma, definisi/makna, serta contoh penggunaan. Elemen non-tekstual contohnya adalah dialek, jenis sintaks, sinonim, antonim dan pelafalan.

Elemen tekstual dapat diisi kontributor secara bebas melalui text-box, sedangkan elemen nontekstual dapat diisi dengan variasi yang mengikuti jenis pilihan isian. Sesuai beban kognitifnya, kontribusi elemen tesktual dapat dibebankan kepada seluruh kontributor, sedangkan kontribusi elemen non-tekstual dapat dibebankan pada kontributor dengan tingkat reputasi tertentu (Tabel 1). 
Setiap elemen mikro utama tersebut dapat disumbangkan secara terpisah-pisah agar kontributor lebih leluasa berkontribusi. Dengan strategi ini, kontributor dapat bebas memilih untuk merekomendasikan kosakata, atau memberikan makna terhadap kosakata yang telah direkomendasikan kontributor lain, memberikan contoh penggunaan, mengisi atribut dialek, sinonim, antonim dan lainnya. Strategi ini juga memberikan peluang lebih besar untuk keragaman kognitif kontributor.

Tabel 1. Jenis pengguna dan kontribusi yang diharapkan

\begin{tabular}{|c|c|c|c|c|c|c|c|c|}
\hline \multirow{3}{*}{$\begin{array}{l}\mathrm{N} \\
\mathrm{O}\end{array}$} & \multirow{3}{*}{$\begin{array}{c}\text { Kel. } \\
\text { Pengguna }\end{array}$} & \multicolumn{7}{|c|}{ Kontribusi } \\
\hline & & Istilah & $\begin{array}{c}\text { Defini } \\
\text { si }\end{array}$ & Cth & Dialek & Sintaks & Antonim & $\begin{array}{c}\text { Sinoni } \\
\mathrm{m}\end{array}$ \\
\hline & & Txt & Txt & Txt & Pil. & Pil. & Link & Link \\
\hline 1 & Guest & $\bar{v}$ & $\sqrt{ } \mathrm{v}$ & $\begin{array}{lll} \\
\checkmark\end{array}$ & $x$ & $x$ & $x$ & $x$ \\
\hline 2 & \begin{tabular}{|l} 
Pengguna \\
Terdaftar
\end{tabular} & $\checkmark$ & $\sqrt{ }$ & v & $x$ & $x$ & $x$ & $x$ \\
\hline 3 & \begin{tabular}{|l} 
Pengguna \\
dengan \\
Daftar \\
Tertentu
\end{tabular} & $\sqrt{ }$ & $\sqrt{ }$ & $\checkmark$ & $\sqrt{ }$ & $\sqrt{ }$ & $\checkmark$ & $\checkmark$ \\
\hline
\end{tabular}

\section{Metode Penelitian}

\subsection{Tahapan Penelitian}

Pada penelitian ini dilakukan beberapa tahapan untuk meningkatkan kontribusi keterbacaan naskah Lontar (Takepan) Sasak. Tahapan yang dilakukan sebagai berikut :

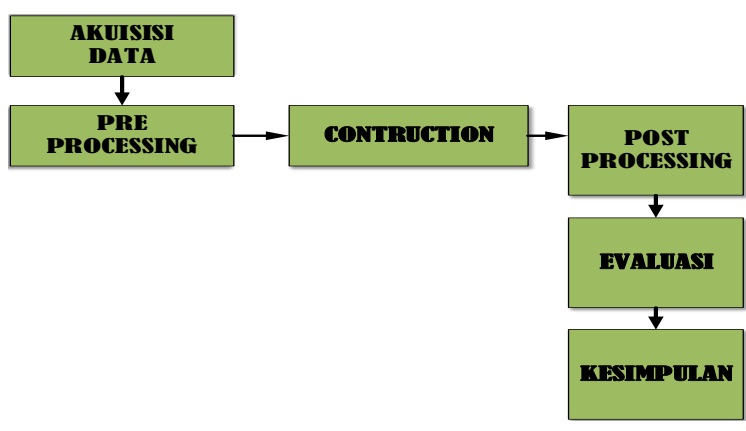

Gambar 2. Tahapan Metode yang diusulkan
1) Akuisisi Data

Ini merupakan tahapan awal untuk memperoleh data dari data analog menjadi data digital yaitu naskah lontar (takepan). Dalam prosesnya menggunakan scanner dengan format JPG dan diperoleh 1,5 s.d 2 Megapixel dari masing masing sample.

\section{2) Pre processing}

Pada tahapan pre processing, proses croping perlu dilakukan pada naskah lontar (takepan) yang ada. Dengan cara menghilangkan bagian yang tidak di perlukan, hingga diperoleh data sample yang sesuai dan digunakan untuk tahap selanjutnya.

\section{3) Contruction}

Kontributor sistem adalah mereka yang aktif bernaskah Lontar (Takepan) Sasak dan terekspose dengan internet. Mereka dapat direkrut sebagai sukarelawan dengan cara mempromosikan sistem pada website dan jejaring sosial tempat mereka berkumpul dan berinteraksi. Termasuk diantaranya adalah bila dilakukan kerjasama dengan komunitas tertentu (rekomendasi : sasak.org) dan mengaplikasikan fitur sosial pada sistem (rekomendasi : facebook social plugin) untuk menyasar jejaring yang dimiliki oleh seorang kontributor.

\section{4) Post Processing}

Kontibutor bebas untuk memilih berkontribusi pada artifak yang diminati sesuai pengetahuan yang dimiliki. Untuk mengambil keputusan 
(kesalahan entri, ejaan, agregasi dibebankan pada kontributor dengan reputasi tertentu.

\section{5) Evaluasi}

Setiap kontribusi pengguna, secara otomatis teragregasi sebagai penyusun kamus baik struktur makro maupun mikronya. Namun demikian terdapat kondisi khusus dimana diperlukan intervensi kontributor secara manual. Kondisi tersebut misalnya adanya kesalahan penulisan/ejaan kosakata, duplikasi entri namun dengan tulisan berbeda, kesalahan pengisian elemen non tekstual, dan lainnya. Hak intervensi dapat diberikan secara otomatis oleh sistem kepada para kontributor dengan reputasi tertentu (berdasarkan kontribusinya). Pemberian hak kepada kontributor untuk mengambil keputusan terhadap kondisi tertentu merupakan salah satu bentuk desentralisasi pengambilan keputusan sebagai pendukung pencapaian wisdom of crowds.

\subsection{Lokasi Penelitian}

Naskah lontar (takepan) sasak yang tersebar di Kota Mataram, Kabupaten Lombok Barat, Lombok Tengah dan Lombok Timur Propinsi Nusa Tenggara Barat.

\section{Hasil dan pembahasan}

Tahapan ini telah menunjukkan sebuah kerangka rancangan untuk digunakan sebagai pedoman pengembangan sistem crowdsourcing kamus naskah Lontar (Takepan) Sasak online. Hasil rancangan ini diharapkan dapat memperkaya basis pengetahuan terkait sistem crowdsourcing dan pencapaian wisdom of crowds.

Usaha lebih lanjut diperlukan untuk mengimplementasikan kerangka rancangan ini menjadi artifak yang yang dapat digunakan di dunia nyata. Dengan penggunaan di dunia nyata tingkat kegunaannya akan dapat teruji, penyempurnaan dapat dilakukan, dan sistem lain yang memiliki ranah persoalan serupa dapat memanfaatkannya sebagai landasan perancangan dan pengembangan sistem.

\section{Kesimpulan}

Berdasarkan penelitian yang sudah di lakukan dapat simpulkan bahwa dalam rancangan kerangka sistem crowdsourcing kamus naskah Lontar (Takepan) Sasak online diperlukan adanya pengembangan dengan tujuan untuk memperbaharui dan mempermudah pengguna dalam mempelajari dan mengkaji serta menterjemahkan aksara sansekerta melalui media online. Pada penelitian selanjutnya dapat dikembangkan lagi menggunakan metode atau algoritma yang lebih baik lagi sehingga dapat menghasilkan inovasi yang dapat bermanfaat untuk kalangan masyarakat secara luas.

\section{Daftar Pustaka}

[1] M. P. Lewis, G. F. Simons, and C. D. Fennig, "Ethnologue: Languages of Honduras Eighteenth edition data," pp. 122, 2015.

[2] "Kamus Base Sasak.pdf." .

[3] D. C. Brabham, "Crowdsourcing as a model for problem solving: An introduction and cases," Convergence, vol. 14, no. 1, pp. 75-90, 2008, doi: 
10.1177/1354856507084420.

[4] A. Doan, R. Ramakrishnan, and A. Y. Halevy, "Crowdsourcing systems on the world-wide web," Commun. ACM, vol. 54, no. 4, pp. 86-96, 2011, doi: 10.1145/1924421.1924442.

[5] D. Geiger, S. Seedorf, T. Schulze, R. Nickerson, and M. Schader, "Managing the crowd: Towards a taxonomy of crowdsourcing processes," 17th Am. Conf. Inf. Syst. 2011, AMCIS 2011, vol. 5, pp. 3796-3806, 2011.

[6] M. P. Lewis and F. Gary, "Simons, and Charles D. Fennig (eds.). 2013," Ethnol. Lang. world, pp. 233-262, 2015.

[7] "Sutriandi, A. Editri. 2010. Pengembangan Model Pencapaian the Wisdom of Crowds pada Wikipedia dalam Kaitannya dengan Wikipedia sebagai Sistem Terapan Computer Supported Cooperative Works . ITB : Tesis Magiste," p. 2010, 2010.

[8] R. Kozinets, A. Hemetsberger, and $\mathrm{H}$. Schau, "The Wisdom of Consumer Crowds," J. Macromarketing, vol. 28, pp. 339-354, Dec. 2008, doi: 10.1177/0276146708325382.

[9] J. Friedrich, "Design science 97," Al Soc., vol. 10, no. 2, pp. 199-217, 1996, doi: 10.1007/BF01205282.

[10] G. Casini and U. Straccia, "Rational closure for defeasible description logics,"
Lect. Notes Comput. Sci. (including Subser. Lect. Notes Artif. Intell. Lect. Notes Bioinformatics), vol. 6341 LNAI, pp. 77-90, 2010, doi: 10.1007/978-3-64215675-5_9.

[11] P. K. Austin, "Clitics in Sasak, eastern Indonesia," 2004.

[12] CrowdsourCing. 2018.

[13] B. Lavoie and L. Dempsey, "Thirteen ways of looking at...digital preservation," D-Lib Mag., vol. 10, no. 7-8, 2004, doi: 10.1045/july2004-lavoie.

[14] M. Saiful and A. M. Nur, "Application of Expert System with Web-Based Forward Chaining Method in Diagnosing Corn Plant Disease Application of Expert System with Web-Based Forward Chaining Method in Diagnosing Corn Plant Disease," Conf. Ser., vol. 1539, pp. $0-7, \quad 2020$, doi: 10.1088/17426596/1539/1/012019.

[15] M. Saiful, "Implementation of the Neural Network ( NN ) Algorithm in Analysis of Student Class Increment Data Based on Report Card Value Implementation of the Neural Network ( NN ) Algorithm in Analysis of Student Class Increment Data Based on Report Card Value .," Conf. Ser., vol. 1539, pp. 0-6, 2020, doi: 10.1088/1742-6596/1539/1/012034. 